\title{
Analisis Pemanfaatan Tidak Langsung Potensi Energi Panas Bumi di Indonesia
}

\author{
Pradipta Ahluriza', Udi Harmoko ${ }^{2}$ \\ ${ }^{1}$ Magister Energi, Sekolah Pascasarjana, Universitas Diponegoro; \\ ${ }^{2}$ Departemen Fisika, Fakultas Sains dan Matematika, Universitas Diponegoro;
}

Email :pradiptaahluriza@students.undip.ac.id (P.A), udiharmoko@fisika.fsm.undip.ac.id (U.H);

\begin{abstract}
Abstrak : Indonesia berkomitmen dalam pengembangan penggunaan energi baru dan terbarukan yang tercantum pada Undang-Undang, Peraturan Pemerintah, Peraturan Presiden, Peraturan Menteri, maupun peraturan pendukung lainnya. Tujuan dari analisis ini adalah untuk mengetahui secara tidak langsung pemanfaatan potensi energi panas bumi di Indonesia. Dengan kondisi geografi Indonesia yang terletak pada zona jalur cincin api, sehingga sistemnya mayoritas bertipe vulcanic (hidrothermal system) yang menyebabkan di setiap lapangannya memiliki potensi yang besar. Potensi ini menjadikannya prioritas pemerintah untuk mencapai bauran energi baru dan terbarukan paling sedikit $23 \%$ pada tahun 2025 dan 31\% pada tahun 2050. Untuk mencapai target ini, pemerintah menentukan arah kebijakan dan rencana strategis yang tercantum pada Rencana Umum Energi Nasional (RUEN). Energi Panas Bumi dapat dimanfaatkan sesuai potensi daya yang dapat dihasilkan, yaitu PLTP.
\end{abstract}

Kata Kunci : Panas Bumi, Hidrothermal System, RUEN

\section{Pendahuluan}

Kebutuhan energi dari waktu ke waktu semakin meningkat seiring dengan kenaikan jumlah penduduk dan kebutuhan akan energi. Pemenuhan kebutuhan energi nasional saat ini masih mengandalkan energi yang berasal dari sumber daya energi fosil, seperti bahan bakar minyak dan gas, dan hanya sebagian kecil atau kurang dari 5\% berasal dari energi baru terbarukan (EBT), termasuk panas bumi. Berdasarkan Peraturan Presiden Republik Indonesia Nomor 22 Tahun 2017 tentang Rencana Umum Energi Nasional (RUEN) memprioritaskan penggunakan energi terbarukan dengan target paling sedikit 23\% pada tahun 2025 dan paling sedikit 31\% pada tahun 2050 (Widyaningsih, 2017).

Indonesia merupakan negara dengan sumber kekayaan alam yang melimpah, salah satunya adalah panas bumi. Hal ini disebabkan secara geologis, Indonesia terletak di daerah jalur gunung api (Ring of Fire), sehingga berpotensi menghasilkan panas bumi. Energi panas bumi sebenarnya mempunyai banyak kelebihan, antara lain bersifat ramah lingkungan bila dibandingkan dengan jenis energi lainnya terutama yang berasal dari fosil, emisi gas $\mathrm{CO}_{2}$ yang dihasilkan dari panas bumi jauh lebih kecil, sehingga bila dikembangkan akan mengurangi bahaya efek rumah kaca yang menyebabkan pemanasan global (Kasbani, 2009). Selain itu, sampai akhir tahun 2019, Indonesia 
Vol. 2, No. 1, pp $53-59$

doi: $10.14710 /$ jebt.2021.11075

memiliki potensi panas bumi sekitar 2.130,6 MW atau sekitar 9\% dari total sumber daya yang dimiliki (Dewan Energi Nasional, 2020).

Berdasarkan potensi energi baru dan terbarukan yang besar, maka pemerintah juga membuat perencanaan dan kebijakan agar penggunakan energi baru dan terbarukan menjadi lebih optimal. Dengan berdasarkan pada data pemanfaatan yang ada, maka dilakukan analisis pemanfaatan tidak langsung potensi energi panas bumi di Indonesia dengan tujuan untuk mengetahui potensi energi panas bumi yang baru berhasil dimanfaatkan sampai saat ini.

\section{Potensi dan Pemanfaatan Energi Panas Bumi di Indonesia}

Energi panas bumi adalah energi yang tersimpan dalam batuan di bawah permukaan bumi dan fluida yang terkandung di dalamnya. Indonesia terletak di daerah jalur gunung api (Ring of Fire), sehingga berpotensi menghasilkan panas bumi. Jalur gunung api tersebut membentang dari ujung barat Sumatera, Jawa, Bali, Nusa Tenggara, Sulawesi dan Maluku.

Daerah lainnya di luar jalur gunung api akf tersebut (non-vulkanik), merupakan daerah busur belakang (Back Arc) yang merupakan daerah sisa-sisa gunung api purba, namun masih terdapat sisa-sisa panas yang juga berpotensi sebagai daerah yang memiliki sumber daya panas bumi, seperti di Bangka Belitung, Papua Barat, Kalimantan Barat, Kalimantan Selatan, Kalimantan Utara, Kalimantan Timur, Riau dan DI. Yogyakarta. Seperti yang terlihat dalam Tabel 1, daerah yang dilalui gunung api ini merupakan daerah (Volcanic Arc) terbesar yang mengandung potensi sumber daya panas bumi sebesar 23.965,5 MW di 351 lokasi yang terdiri dari sumber daya spekulaf sebesar 5.952 MW, sumber daya hipotek sebesar 3.387 MW dan total cadangan sebesar 14.626,5 MW. Pemanfaatan potensi panas bumi tersebut sampai dengan tahun 2019 baru tercapai sebesar 2.130,6 MW atau 9\% dari total sumber daya yang dimiliki. Potensi panas bumi terbesar terdapat di Pulau Sumatera dengan cadangan sebesar 5.846 MW, Pulau Jawa dengan cadangan sebesar 5.652 MW dan Pulau Sulawesi dengan cadangan sebesar 1.341 MW (Dewan Energi Nasional, 2020).

Tabel 1.

Sumber Daya Panas Bumi Per Wilayah (Badan Geologi KESDM, 2019)

\begin{tabular}{|c|c|c|c|c|c|c|c|c|}
\hline \multirow{3}{*}{ No. } & \multirow{3}{*}{ Pulau } & \multicolumn{7}{|c|}{ Sumber Daya (MW) } \\
\hline & & \multirow{2}{*}{ Lokasi } & \multirow{2}{*}{ Spekulatif } & \multirow{2}{*}{ Hipotetik } & \multicolumn{3}{|c|}{ Cadangan } & \multirow{2}{*}{$\begin{array}{l}\text { Kapasitas } \\
\text { Terpasang }\end{array}$} \\
\hline & & & & & Mungkin & Terduga & Terbukti & \\
\hline 1 & Sumatera & 101 & 2.276 & 1.557 & 3.735 & $1.040,7$ & $1.070,3$ & 744,3 \\
\hline 2 & Jawa & 73 & 1.265 & 1.190 & 3.414 & 418 & 1.820 & $1.253,8$ \\
\hline 3 & Bali & 6 & 70 & 21 & 104 & 110 & 30 & 0 \\
\hline 4 & Nusa Tenggara & 31 & 190 & 148 & 892 & 121 & 12,5 & 12,5 \\
\hline 5 & Kalimantan & 14 & 151 & 18 & 13 & 0 & 0 & 0 \\
\hline 6 & Sulawesi & 90 & 1.365 & 362 & 1.041 & 180 & 120 & 120 \\
\hline 7 & Maluku & 33 & 560 & 91 & 497 & 6 & 2 & 0 \\
\hline 8 & Papua & 3 & 75 & 0 & 0 & 0 & 0 & 0 \\
\hline \multirow{3}{*}{\multicolumn{2}{|c|}{ Total }} & \multirow{3}{*}{351} & \multirow{2}{*}{5.952} & \multirow{2}{*}{3.387} & 9.696 & $1.875,7$ & $3.054,8$ & \multirow{3}{*}{$2.130,6$} \\
\hline & & & & & & $14.626,5$ & & \\
\hline & & & & & $23.965,5$ & & & \\
\hline
\end{tabular}


Panas bumi yang dikembangkan menjadi sumber energi melalui Pembangkit Listrik Tenaga Panas Bumi (PLTP) merupakan energi yang bersifat terbarukan, karena panas yang dihasilkan bersifat konstan dan tetap ada sepanjang aktifitas bumi berlangsung. Oleh sebab itu, potensi panas bumi perlu terus dikembangkan dari aspek sumber daya menjadi cadangan hingga menjadi PLTP. Potensi panas bumi menghasilkan rata-rata energi listrik sebesar $50 \mathrm{MW}-100 \mathrm{MW}$ per pembangkit, maka secara nasional peran energi baru dan terbarukan secara signifikan (Dewan Energi Nasional, 2020).

Jumlah kapasitas terpasang untuk Pembangkit Listrik Tenaga Panas Bumi dihitung dari jumlah kapasitas PLTP yang telah mencapai Commercial Operation Date. Sepanjang triwulann I hingga triwulan IV tahun 2019, capaian penambahan kapasitas terpasang panas bumi sebesar 2.130,7 MW atau 100,1 \% terhadap target yang ditentukan tahun 2019 (Direktorat Jenderal Energi Baru, Terbarukan, 2018).

\section{Arah Kebijakan, Strategi dan Regulasi Pemerintah Berkaitan Energi Panas Bumi}

Pengembangan energi baru dan terbarukan di Indonesia memiliki beberapa dasar hukum yang mendukung. Mulai dari Undang-Undang (UU), Peraturan Pemerintah (PP), Peraturan Presiden (Perpres), Peraturan Menteri (Permen), dan peraturan terkait lainnya.selain itu, didukung juga dengan strategi yang dilakukan oleh kementerian ESDM untuk mencapai visi dan misi Indonesia dalam mengembangkan energi baru dan terbarukan.

Arah dari kebijakan energi panas bumi adalah sebagai berikut.

1) Meningkatkan eksplorasi panas bumi dan membuat perkiraan biaya yang layak pada lokasi yang berbeda-beda.

2) Memastikan status tata guna lahan di hutan-hutan yang memiliki potensi panas bumi.

3) Mengkaji implementasi peraturan perundang-undangan di sektor panas bumi untuk mendekatkan sektor hulu dan hilir.

4) Melakukan penyempurnaan di dalam pengelolaan dan persyaratan tender panas bumi, yang meliputi pendelegesian kepada PLN untuk melaksanakan tender, pembagian resiko yang menguntungkan antara PLN dan pengembang, harga jual dan mekanismenya serta pembinaan untuk skala kecil dan penyehatan BUMN.

5) Meningkatkan kemampuan dalam negeri untuk mendukung kegiatan eksplorasi dan industri pendukung kelistrikan.

Regulasi pemerintah terkait energi panas bumi meliputi :

- Undang-Undang No. 21 Tahun 2014 tentang Panas Bumi.

- Peraturan Pemerintah No. 28 Tahun 2016 tentang Besaran dan Tata Cara Pemberian Bonus Produksi Panas Bumi.

- Peraturan Pemerintah No. 7 Tahun 2017 tentang Panas Bumi Untuk Pemanfaatan Tidak Langsung.

- Peraturan Menteri ESDM Nomor 18 Tahun 2012 tentang Perubahan Atas Peraturan Menteri ESDM Nomor 11 Tahun 2009 tentang Pedoman Penyelenggaraan Kegiatan Usaha Panas Bumi.

- Peraturan Menteri ESDM Nomor 14 Tahun 2013 tentang Status Kepemilikan Aset Panas Bumi Yang Berasal Dari Kontrak Operasi Bersama (Joint Operation Contract). 
- Peraturan Menteri ESDM Nomor 17 Tahun 2014 tentang Pembelian Tenaga Listrik Dari PLTP Dan Uap Panas Bumi Untuk PLTP Oleh PT. Perusahaan Listrik Negara (Persero).

- Peraturan Menteri ESDM Nomor 35 Tahun 2014 Tentang Pendelegasian Wewenang Pemberian Izin Usaha Ketenaga Listrikan Dalam Rangka Pelaksanaan Pelayanan Terpadu Satu Pintu Kepada Kepala Badan Koordinasi Penanaman Modal.

- Peraturan Menteri ESDM Nomor 14 Tahun 2015 tentang Tata Cara Pengenaan, Pemungutan, Dan Penyetoran Penerimaan Negara Bukan Pajak Yang Berasal Dari Kegiatan Panas Bumi Pada Direktorat Jenderal Energi Baru, Terbarukan, Dan Konservasi Energi.

- Peraturan Menteri ESDM Nomor 44 Tahun 2016 tentang Tata Cara Penempatan Serta Pencairan Komitmen Eksplorasi Panas Bumi.

- Peraturan Menteri ESDM Nomor 14 Tahun 2017 tentang Perubahan Atas Peraturan Menteri ESDM Nomor 35 Tahun 2014 tentang Pendelegasian Wewenang Pemberian Izin Usaha Ketenagalistrikan Dalam Rangka Pelaksanaa Pelayanan Terpadu Satu Pintu Kepada Kepala Badan Koordinasi Penanaman Modal.

- Peraturan Menteri ESDM Nomor 23 Tahun 2017 tentang Rekonsiliasi, Penyetoran, Pengenaan dan Tata Cara Penetapan Presentase Daerah Penghasil Atas Besaran Bonus Produksi Panas Bumi.

Berikut ini merupakan arah kebijakan nasional dan kementerian terkait pengembangan pembangkit listrik tenaga panas bumi (PLTP) berdasarkan Rencana Strategis Ditjen EBTKE 2020-2024.

a. Pemberian insentif sebagai Levelized Cost of Electricity (LCOE) sebagai perwujudan reimbursement terhadap biaya-biaya yang pada hakikatnya bukan tanggung jawab pengembang;

b. Fasilitasi akses pendanaan proyek;

c. Regulasi dan advokasi untuk pemanfaatan di kawasan konservasi;

d. $S^{\circ}$ Cial-engineering untuk dukungan masyarakat;

e. Penciptaan demand dengan pengembangan klaster ekonomi;

f. Integrasi dan kolaborasi dalam sistem pengelolaan dan perbaikan tata kelola.

g. Pengembangan Flores geothermal island.

\section{Teknologi Pemanfaatan Panas Bumi}

Salah satu alternatif pengembangan panas bumi untuk energi listrik adalah dengan teknologi pusat listrik siklus biner terutama untuk kualitas sumur geothermalnya yang berentalpi rendah. Teknologi ini terbagi dalam dua siklus operasi yakni siklus fluida geothermal dan siklus fluida organik, selain siklus fluida air pendingin. Fluida sebagai penggerak turbin adalah berupa propane (Tompodung \& Pangow, 2009).

\subsection{Sistem Dry Steam}

PLTP sistem dry steam mengambil sumber uap panas dari bawah permukaan. Sistem ini dipakai jika fluida yang dikeluarkan melalui sumur produksi berupa fasa uap. Uap tersebut yang langsung dimanfaatkan untuk memutar turbin dan kemudian turbin akan mengubah energi panas bumi menjadi energi gerak yang akan memutar generator untuk menghasilkan energi listrik. 
Vol. 2, No. 1, pp $53-59$

doi: $10.14710 /$ jebt.2021.11075

Syarat dari sistem Dry Steam adalah mempunyai suhu yang relative tinggi $\left(>230^{\circ} \mathrm{C}\right)$, Memiliki teakanan uap yg cukup besar ( $>3,5 \mathrm{~atm})$, memiliki volume uap yg cukup banyak (10 ton/jam atau setara $1000 \mathrm{~kW}$ listrik), letaknya tidak terlalu dalam dari permukaan bumi (maks 2500 meter), dan fluidanya tidak bersifat korosif (Hasbullah, 2009).

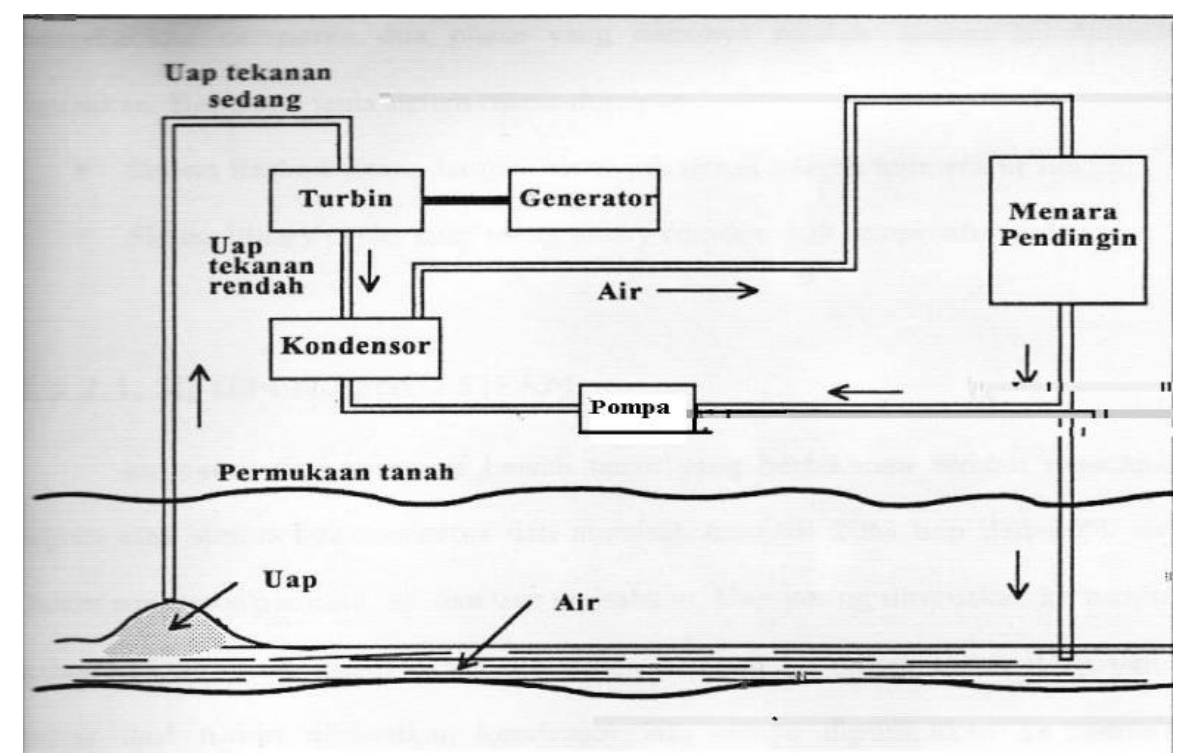

Gambar 1. Skema Sistem Dry Steam (Hasbullah, 2009)

\subsection{Sistem Binary}

Salah satu alternatif pengembangan panas bumi untuk energi listrik adalah dengan teknologi pusat listrik siklus biner, terutama untuk kualitas sumur geothermal yang berentalpi rendah. Teknologi ini terbagi dalam dua siklus operasi, yakni siklus fluida geothermal dan siklus fluida organic, selain siklus fluida air pendingin (Tompodung \& Pangow, 2009).

Pada dasarnya cairan panas bumi yang digunakan untuk pembangkit listrik adalah cairan yang memiliki suhu $200^{\circ} \mathrm{C}$, namun cairan panas bumi suhu sedang $\left(100^{\circ} \mathrm{C}-200^{\circ} \mathrm{C}\right)$ dapat digunakan dengan cara memanaskan cairan organik yang memiliki titik didih rendah, uapnya kemudian digunakan untuk meggerakan turbin (Hasbullah, 2009).

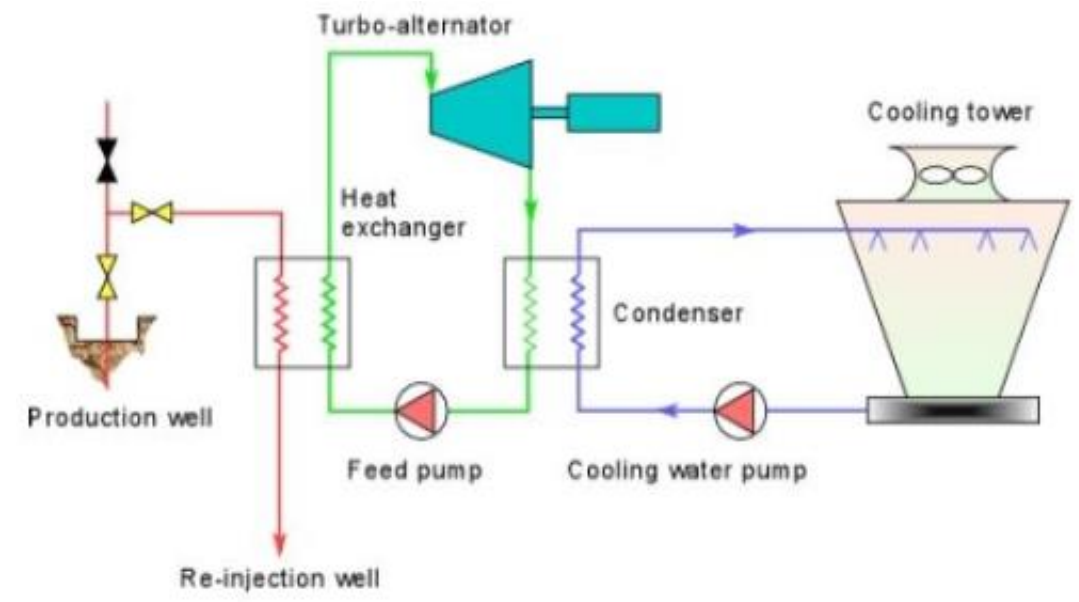

Gambar 3. Siklus Biner (Adi, 2012) 
Vol. 2, No. 1, pp $53-59$

doi: $10.14710 /$ jebt.2021.11075

\subsection{Sistem Flash}

PLTP sistem Flash Steam merupakan PLTP yang paling umum digunakan. Pembangkit jenis ini memanfaatkan reservoir panas bumi yang berisi air dengan temperatur lebih besar dari $182^{\circ} \mathrm{C}$. Air yang sangat panas ini dialirkan ke atas melalui pipa sumur produksi dengan tekanannya sendiri, karena mengalir keatas, tekanannya menurun dan beberapa bagian dari air menjadi uap. Uap ini kemudian dipisahkan dari air dan dialirkan untuk memutar turbin. Sisa air dan uap yang terkondensasi kemudian disuntikkan kembali melalui sumur injeksi kedalam reservoir, yang memungkinkan sumber energi ini berkesinambungan dan terbaharui.

Sistem Flash dibagi menjadi Single Flash Steam dan Double Flash Steam. Single Flash Steam digunakan jika cairan di mulut sumur dalam kondsi cairan jenuh. Cairan dialirkan ke sebuah flasher agar menguap. Tekanan flasher mempengaruhi banyaknya uap yang dihasikan, lalu dialirkan ke turbin (Insani, 2019). Skema Single Flash Steam ditunjukkan dalam Gambar 4.

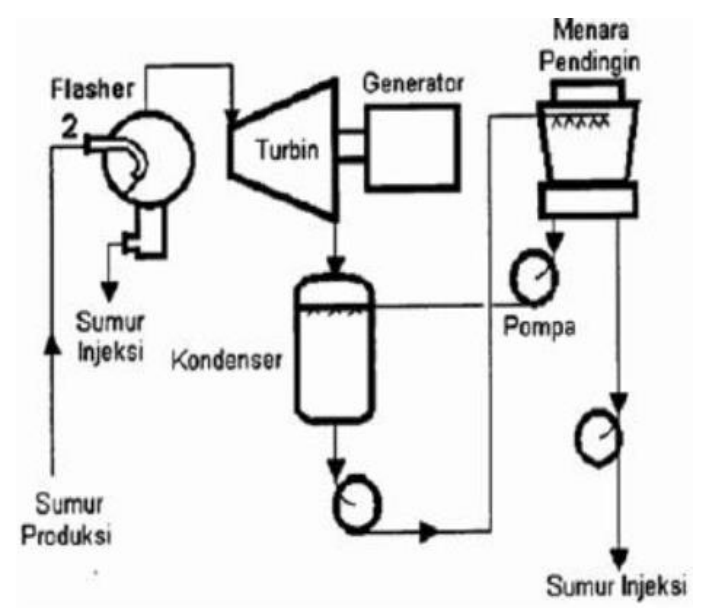

Gambar 4. Skema Single Flash Steam (Insani, 2019)

Sedangkan Double Flash Steam menggunakan dua pemisah cairan yaitu separator \& flasher dan menggunakan dua turbin, yaitu HP turbin (turbin tekanan tinggi) \& LP turbin (turbin tekanan rendah) dan disusun ganda (Insani, 2019). Gambar 5 menunjukkan skema dari Double Flash Steam.

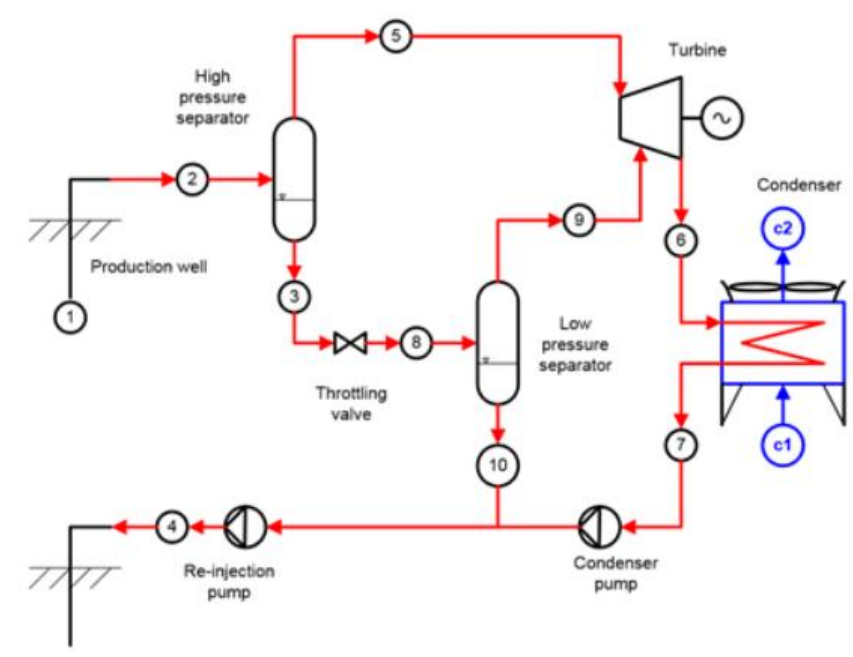

Gambar 5. Skema Double Flash Steam (Baihaqi et al., 2017) 


\section{Kesimpulan}

Potensi energi panas bumi di Indonesia sebesar 523.965,5 MW di 351 lokasi yang terdiri dari sumber daya spekulatif sebesar 5.952 MW, sumber daya hipotetik sebesar 3.387 MW dan total cadangan sebesar 14.626,5 MW. Namun, hingga saat ini energi yang dimanfaatkan baru mencapai 4.9\%. Pemerintah menargetkan bauran energi baru dan terbarukan pada tahun 2025 paling sedikit sebesar $23 \%$ dan $31 \%$ pada tahun 2050. Dengan potensi yang besar pembangunan PLTP menjadi prioritas pemerintah dalam meningkatkan bauran energi baru dan terbarukan. Pada Rencana Umum Energi Nasional (RUEN), pengembangan panas bumi untuk tenaga listrik diproyeksikan sebesar 7,2 GW pada tahun 2025 dan 17,6 GW pada tahun 2050. Untuk menunjang rencana tersebut, pemerintah yang diwakilkan oleh Direktorat Jenderal EBTKE membuat kebijakan dan rencana strategis.

\section{Daftar Pustaka}

Adi, A. P. (2012). Pengaruh Waktu Penahanan Hidrotermal Terhadap Karakteristik Zeolit Yang Disintesis Dari Limbah Geothermal. 5-35.

Baihaqi, R. T. A., Sinulingga, H. P. K., \& Hamdani, M. R. (2017). Tekanan Flashing Optimal Pada Pembangkit Listrik Tenaga Panas Bumi Sistem Double-Flash. VI, SNF2017-ERE-1-SNF2017-ERE10. https://doi.org/10.21009/03.snf2017.02.ere.01

Dewan Energi Nasional. (2020). Bauran Energi Nasional.

Direktorat Jenderal Energi Baru, Terbarukan, dan K. E. (2018). Laporan Kinerja Tahun 2017. Kementerian Energi Dan Sumber Daya Mineral, 3, 1-50.

Hasbullah. (2009). Konversi energi panas bumi.

Insani, N. A. (2019). Analisis Keekonomian Pembangkit Listrik Tenaga Panas Bumi Kapasitas Kecil Sistem Siklus Uap. EPIC : Journal of Electrical Power, Instrumentation and Control, 2(2), 1-7. https://doi.org/10.32493/epic.v2i2.2911

Kasbani, K. (2009). TIPE SISTEM PANAS BUMI DI INDONESIA DAN ESTIMASI POTENSI ENERGINYA. Buletin Sumber Daya Geologi, 4(3). https://doi.org/10.47599/bsdg.v4i3.184

Tompodung, A., \& Pangow, T. T. V. (2009). Pemanfaatan Panas Bumi Sebagai Sumber Energi Alternatif Sulawesi Utara. November 2008, 1-9.

Widyaningsih, G. A. (2017). Peraturan Presiden Nomor 22 Tahun 2017 tentang Rencana Umum Energi Nasional. Jurnal Hukum Lingkungan Indonesia, 4(1). https://doi.org/10.38011/jhli.v4i1.53 